Visualizing Objects, Places, and Spaces: A Digital Project Handbook

\title{
Budgets \& Funding for Archival Projects
}

Beth Fischer, Hannah Jacobs, Claire Cahoon, Noah Huffman

Published on: Oct 14, 2019

DOI: 10.21428/51bee781.ce977d63

License: Creative Commons Attribution 4.0 International License (CC-BY 4.0). 


\section{What do you need money for and when do you need it?}

Archival projects can be very cheap: a text-only spreadsheet created by a single person to record items related to their own research is an archive. They also can be very costly, involving large teams who need to store and access videos, $3 \mathrm{~d}$ models, or other large file types, and who create custom interfaces for a public audience. This wide range of project scales and the tendency of archival projects to grow over time can make it difficult to estimate the costs of such a project.

Think about these factors when estimating a project budget.

- Do I need to pay for other tools to collect, store, or process my content? As you think through your workflow, consider what programs or tools you might need to acquire, process, format, store, and share your archive. The cost of one tool versus another might be a good reason to change your process slightly.

- Physical equipment: Do you need new or upgraded computers, cameras, or recorders? Will you need to buy these, or is it possible to borrow or rent them? When does renting become more expensive than buying? Your institution may have higher-level equipment that you can borrow for specific projects. Start with places like the library, IT department, or media lab, but also consider specific departments within the institution that are likely to have people working on projects that require this equipment. Is there a journalism or communications program? How about the computer science department, or the art department? Even if they can't provide you with equipment directly, they may have negotiated special rates with vendors.

- Special software or digital tools: One consideration with programs is whether you are paying for a piece of software you purchase once and install yourself, or whether you are paying for software-as-a-service, where you pay for a subscription to a special program. Website management and web hosting tools are often in this category. These subscription-based programs are becoming more and more common, and they are often cheaper short term but can add up when you have a project going on over several years. Another consideration is how many licenses or logins you need to buy. Can you install that piece of software on multiple 
computers? Can you have your whole team using one login, or do you need people to have different levels of access or to be working simultaneously?

You can keep your software costs lower by using a program that your institution has already purchased and made available, even if you still have out-of-pocket costs. It is also worth contacting a company to ask whether they have educational or non-profit discounts; sometimes these are not advertised publicly and a single email can save you a lot of money. You can also try searching "free version of paid_software_name" to find recommendations for alternatives to expensive tools, though the tradeoff is usually that free tools have more limited capability, and often have a less user-friendly interface and require more training.

- Storage space: Storage is often overlooked as a cost. Consider your storage needs for the initial project, plus an estimate for how much growth might occur in 3-5 years. When that much time has passed, storage costs and platform options will likely have changed enough that your estimates will no longer be applicable.

Many programs and platforms for storing archival materials offer a free level for relatively small projects, then require payment for larger quantities of data. Often this is computed by the amount of space you need (usually measured in MB, TB, or GB), although some programs also charge by the number of tables or records.

For a small project, you also might be able to store all your content locally on your hard drive or on an external hard drive. While an external hard drive may cost more up front, you would have fewer ongoing costs than you would by paying for storage space online. It is especially important to have a robust backup plan if you do decide to use local storage of this type, though, so factor that into your costs as well! Configuring your hard drive can also add costs if you need to hire someone to help.

Another way to keep this cost low is to explore whether your institution provides server storage or something similar for its faculty and staff. Contact a librarian or someone in a research technology department to find out whether this is an option for you.

Depending on the tools you choose for the rest of your project, you may find that a 
certain quantity of storage space is included in the cost of something else. For example, website platforms like Wordpress often include some storage space, as do some commonly used managed-hosting platforms like Reclaim Hosting. This may be less expensive than standalone storage.

- How much funding do I need for labor or contract work? Labor costs can be a big part of digital projects, in part because many people underestimate how much time collecting, cleaning, and formatting data can take. Labor for specialized expertise, like database programming, can also be expensive. To estimate your labor costs, consider:

-What tasks does someone else need to do, either because I don't have the time or because it is a skill I don't have and can't/won't acquire? How much time will these take? Be as specific as possible, and try to estimate how long these tasks will take and when in your process you will need someone to perform them. When you prototype your project or test your workflow, time each of the steps. It is very easy to underestimate how much time it takes to make content ready for use on a computer. And, of course, if you have special subject expertise, make sure that you keep that in mind in your time estimates. A undergraduate student researcher who is relatively new to the field, for example, will likely work through source material much more slowly than a graduate student in the field. Based on this, you may find that it is worth the extra cost of a special software program to make work go faster and reduce your labor costs.

-What skills do these tasks require, and how specialized are those skills? Does your work require someone who can read a foreign language? Someone who has photography experience? Someone who can use SQL? Many of the tasks that we think of as specialized or rare within one field are common in another, and you want to be as specific as possible when you hire, especially if you will be trying to hire a student or freelance contractor.

- What extra costs beyond the wage will be included with this labor? This includes monetary costs like taxes or overhead that may be passed on to you if you hire a student worker, but there might also be time- or effort-based costs like training to consider when deciding whether to hire someone to do work. 


\section{You want to make sure you pay people fairly for the work they do for you, but there are still appropriate ways to keep labor costs reasonable.}

Being specific and having a clearly defined and limited work plan will save a lot of time and help keep hourly costs lower. When you test your workflow, you may also find that paying more for an advanced piece of software costs less over the course of the project than paying for someone to use a tool that takes more time.

If you are at a college or working in an institution like a museum or non-profit, you may be able to structure an internship that helps with your project. As with any collaboration, an internship should be of value to the person who is working with you and not just a way for you to avoid costs, so make sure that the role offers real skill development and that you have the time to include mentorship and guidance.

Some institutions also have work-study programs in which a faculty or staff member can propose a student position. In this situation, the institution or federal money subsidizes part of the cost of hiring the student. This is usually only feasible when the position is months or years long, and does require additional commitments in time and administrative overhead, but it can help keep direct costs low.

- Do I need to buy licenses or otherwise pay for copyrighted material? If you are using the archive solely for your own back-end research, you are unlikely to need to pay for licenses or rights to reproduce materials, but you may need to pay to acquire the original source documents. However, if you expect to make your archive available to others, you will need to secure permission, and this can sometimes involve an additional cost. These costs can vary significantly, and it is wise to get an estimate directly from the owners of the source material. In many cases, they will be willing to negotiate a lower or waived price for educational or non-profit purposes.

- Do I need all the money upfront? Costs like programs and special equipment often come early in an archival project, but there are a lot of ways to keep the other costs minimal at the beginning. This can help you build enough of a project to troubleshoot your workflow, make better estimates on time and labor needs, and even build a sample project with more limited data or functionality. This experience, especially when you have a simple version of your project available, can make you much more competitive for grants that can fund later expansions of your work. It can also make it easier to hire someone to help as you can be much more specific about your needs. 


\section{Funding resources for archival processes \& special considerations for grant applications}

Grants for archival work often require that the archives be made publicly accessible or reach an underserved audience. Archives grants are also frequently directed toward preserving source materials that are threatened. Some digital humanities grants also focus on novel structures or processes for archives, but these usually require considerable institutional backing and larger teams, because the goal in such cases is about the archival process itself rather than the archive's contents.

It can be particularly hard to find digital humanities funding for the earlier stages of a larger research project, as this organization is usually considered part of the standard research process. For that reason, it is often more productive to look for grant support within your research field rather than through digital humanities channels.

\section{When applying for a digital humanities grant for an archival project:}

- Show how the structure and affordances of your project design accomplish something that is more than just putting resources online. How does the processing of the archival material or the interface you have for using it further goals that were not already met?

- Be very specific about timeline and technical tools/processes. Grant reviewers have seen a lot of grandiose proposals that end up being unachievable. With archives grants in particular, you want to make sure you communicate how you will acquire and process the source material, and give good reasoning for your estimates of how much material you can include.

\section{When writing an application for an archives project for a subject-specific grant, make sure to address:}

- Exactly what your archive encompasses, and what relationships or connections among material it produces.

- Why the archive needs a digital format, and what this particular format does that other formats wouldn't.

- How this project could be used for other research in the field, or for pedagogical or other expanded purposes. This can be especially helpful if your project solves subjectspecific archival needs, like ways to encode unique aspects of content in your field. 
- The technological requirements of your project and how you will achieve them through your own expertise, existing programs, or identified collaborators.

Continue reading: Documentation for an Archival Project 